\title{
Estratégias textuais para a produção de resumos para avaliação por alunos do ProFIS
}

\author{
Naomi Kawakami (IC)
}

\begin{abstract}
Resumo
Este trabalho procura descrever as estratégias de elaboração de resumo utilizadas por alunos do ProFIS (Programa de Formação Interdisciplinar Superior) da Unicamp numa prova de uma disciplina obrigatória no primeiro semestre de 2014. A base teórica que fundamenta a análise é a dos estudos de produção do resumo acadêmico enquanto gênero textual. O resultados apontam para uma leitura linear norteada por elementos anteriores ao texto e estratégias de cópia e decalque do texto fonte.
\end{abstract}

Palavras Chave: Resumo, Estratégias de escrita, Estratégias de leitura

\section{Introdução}

Este trabalho analisa os resumos de alunos do ProFIS (Programa de Formação Interdisciplinar Superior) da Unicamp produzidos como parte de uma avaliação de uma disciplina de leitura e produção de textos acadêmicos no primeiro semestre de 2014. O objetivo da análise é descrever as estratégias de elaboração dos resumos, tratado tanto de leitura quanto de produção escrita, e compará-las aos resultados presentes na literatura. Para tanto, a base teórica é a de estudos sobre resumos (BROWN \& DAY, 1983; HOWARD, 1992; KLEIMAN, 1989; TELES, 2007) e estudos sobre leitura (KLEIMAN, 1993; 2011).

\section{Resultados e Discussão}

$\mathrm{Na}$ análise, procurou-se, inicialmente, identificar as estruturas selecionadas no texto fonte e como essas estruturas estão reproduzidas nos resumos estudados. Nessa primeira etapa, os textos apontaram para grande similaridade entre os trechos retirados do texto fonte e as passagens correspondentes dos resumos, assim como uma leitura linear, mas que começa a ultrapassar as estruturas de organização - em especial os parágrafos - do texto fonte.

Em uma segunda etapa, procurou-se identificar no texto fonte e no comando da tarefa pistas para a compreensão das estratégias de leitura e escrita utilizadas pelos alunos. Nessa análise, pôde-se observar a utilização de elementos anteriores ao corpo do texto, no caso, o subtítulo e título, como guias para a seleção de informações para a elaboração dos resumos.

\section{Conclusões}

A comparação entre os resultados observados nas análises dos resumos e a base teórica indica que, enquanto parte das estratégias identificadas correspondem àquelas descritas na literatura, a produção dos alunos também trouxe novas informações sobre tanto a leitura realizada norteada pela produção posterior do resumo e a situação avaliativa na qual estava inscrita quanto a produção escrita - especialmente com relação à organização das informações selecionadas no texto fonte.

\section{Agradecimentos}

À Prof. a Dr. a Inês Signorini.

Aos alunos do ProFIS da disciplina LA083 de 2014.

\footnotetext{
BROWN, A. L. \& DAY, J. D. Macrorules for Summarizing Texts: The Development of Expertise. Journal of Verbal Learning and Verbal Behavior. Technical Report No. 270. 1983.

${ }^{2}$ HOWARD, R. M. (1992). A Plagiarism Pentimento. Journal of Teaching Writing. v. 11.n. 2. p233-45. 1992

${ }^{3}$ KLEIMAN, A. Leitura: Ensino e Pesquisa. Campinas, SP: Pontes. P. 75-90. 1989

${ }^{4}$ KLEIMAN, A. Oficina de leitura: teoria e práica. Campinas, SP: Editora da Universidade Estadual de Campinas. Cap. 6, p. 67-81. 1993

${ }^{5}$ KLEIMAN, A. Texto e leitor: Aspectos Cognitivos da Leitura. 14 Edição, Campinas, SP: Pontes Editores. 2011

${ }^{6}$ TELES, M. E. S. Um estudo do resumo acadêmico em curso de graduação. Dissertação (Mestrado). Pontifícia Universidade Católica de São Paulo. 2007
} 